DOI 10.37882/2500-3682.2021.01.09

\title{
КОУЧИНГ: КРАТКАЯ ИСТОРИЯ И ВОЗМОЖНОСТИ
}

\section{COACHING: A BRIEF HISTORY AND OPPORTUNITIES}

\section{A. Machukha \\ O. Vasilyeva}

Summary: The article analyzes coaching as a phenomenon that not only acts as a new direction of psychological counseling, actively using modern psychotechnology's focused on the effective achievement of the intended goals, but also a phenomenon that has received wide application, going beyond counseling, combining the concepts of various psychological schools and directions in a single content. The study reveals the distinctive features of coaching in the context of helping a person to solve their own problems, as well as presents opportunities for building individual trajectories of human development through coaching. Deep analysis presented in the information sources data allowed to identify the possibility of coaching in the organization of subject-subject interaction profiling of active position of the learner, presenting it in an innovative mentoring, contributing to develop a person's own position in life, goals, objectives and plans with partnerships in the provision of the right of choice in making decisions and in terms of acceptance of responsibility for the choice. The study focuses on the consideration of the basis of the specifics of organizational coaching, which provides an opportunity to create a new system of non-financial motivation of personnel. The results of the study can be useful for specialists in various fields and spheres of human life.

Keywords: coaching, opportunities, importance of application, the same content, concepts, personality.

\author{
Мачуха Александр Михайлович \\ Соискатель, Южный федеральный университет \\ aleksandrinfo@bk.ru \\ Васильева Ольга Семеновна \\ К.б.н., профессор, Южный федеральный университет \\ vos@sfedu.ru
}

Аннотация: В статье осуществлен анализ коучинга как явления не только выступающего в качестве нового направление психологического консультирования, активно использующего современными психотехнологиями, ориентированными на эффективное достижение намеченных целей, но и феномена, получившего широкое прикладное применение, выходящего за рамки консультирования, объединяя в единой содержание концепции различных психологических школ и направлений. В ходе исследования выявлены отличительные особенности коучинга в контексте помощи человеку в его собственном решении проблемы, а также представлены возможности посредством коучинга выстраивания индивидуальных траекторий развития человека. Глубокий анализ, представленных в информационных источниках данных позволил выделить возможности коучинга в организации субъект-субъектного взаимодействия с профилированием активной позиции у обучаемого, представив его в виде инновационного вида наставничества, способствующего выработки у человека собственной жизненной позиции, целей, задач и планов при партнерских отношений, при предоставлении права выбора в принятии решений и в условиях принятия им ответственности за производимый выбор. В исследовании акцентировано внимание на рассмотрении основы специфики организационного коучинга, предоставляющей возможность создать создает систему нефинансовой мотивации персонала. Результаты исследования могут быть полезны для специалистов различных областей и сфер жизнедеятельности человека.

Ключевые слова: коучинг, возможности, прикладное значение, единое содержание концепций, личность.

Мы не беремся отражать свое мнение по поводу конкретной принадлежности коучинга к той или иной области человекознания (философия, психология, педагогика), но заметим, что в настоящее время он получил широкое прикладное применение (менеджмент, образование, психология личностного роста, акмеология и др.; разрабатываются модели коучинга в медицине, образовании, спорте, работе с детьми дошкольного возраста, ведении бизнеса и пр.) и сферы его применения растут. Одним из «осевых» девизов коучинга в образовании является «коучинг не учит, он помогает учиться», т.е. открывать человеку самого себя, свои резервы и возможности, что разительно отличает его от большинства методов психологии и психотерапии: коучинг не ориентирован на анализ прошлого, но «настроен» на поиск внутренней мотивации быть ориентированным в будущее [10].

Особенностью современной психологии является стремление соединить в сколь «сводимое» единое со- 
держание концепций различных психологических школ и направлений, а также «заимствование» и развитие ею аспектов понимания человека из философии, социологии, но, также, в силу сложности и многоаспектности и самой человеческой жизни, и человека как специфического явления особенностей его отношений в мире экономики, политики и т.д. При этом «формальную» психологию как науку о «душе» (психическом) все более обогащают идеи, развиваемые в изначально отличных от нее областях человекознания - лингвистики и программирования (Дж. Гриндер - профессор лингвистики, Р. Бэндлер - математик и программист - основатели нейро-лингвистического программирования, имеющего неоднозначный отклик в классической науке), культурологии и философии (М. Де Серто, М. Оже, 3. Бауман и др. развитие идеи «не-места» и представления, в частности, об аде как преимущественно о женском и рае как о преимущественно мужском [17]; понимание трансового с измененным состоянием сознания характера многих религиозных практик $[13,18])$ и др.

Неоспоримым фактом в познании человеком и мира, и себя, является то, что мы вынуждены производить это познание ценой опыта, иногда ошибочного и болезненного, и многое, если не большинство, здесь начинается с того, что человек сначала делает, о потом понимает смысл сделанного. Фактом является и то, что человек лучше понимает то, что он сделал сам, нежели то, что ему задано (можно сказать «свыше», но можно употребить и другой термин - «природой»). Социальные явления и отношения «заданы» (или «задаваемы») прежде всего самим человеком (человечеством), но и в них очень много неосознаваемого, «теряемого» в истории и культуре, имеющего потаенный смысл и пр. Очень часто человек не предумышленно совершает ошибки в своем развитии, но заблуждается. Однако силу своего заблуждения или же близости к истине человек в большинстве случаев может проверить лишь опытным путем, а это требует времени. Точно также и с новыми явлениями, к которым мы бы хотели отнести и коучинг, эффективность которого уже сейчас признается не только заинтересованными в его продвижении коучами, но и их последователями. Попробуем разобраться в самом явлении коучинга.

Слово «коучинг», полностью укорененное в английском языке и образованное от «коуч» - тележка, экипаж, карета, но заимствованное из венгерского «коча» - конная тележка, повозка, позже стало обозначать «тренировку», «репетиторство», «наставничество», и, в начале, обозначало осуществление помощи студентам в подготовке к экзаменам, и более всего оно нашло свое первоначальное укоренение в спорте, где его первое упоминание принадлежит педагогу-теоретику Гарварда Тимоти Гэллуэю (или Голви, Геллвей, родившемуся в 1938 г. и ныне здравствующему), употребившему вместе со словом «коучинг» понятие «внутреннего исследова- теля» и подразумевавшего под ним душевное состояние спортсмена [5]. Ему же принадлежит и столь цитируемая фраза о том, что «коучинг не учит, а помогает учиться». Основная идея работы состоит в настрое спортсмена «победить своего внутреннего врага» - страхи, комплексы, внутренние ограничения, что во многом и является залогом победы над соперником. Таким образом, по Г.Т. Геллуэю коучинг призван максимально раскрыть потенциал человека, что и позволяет существенно расширить его собственную эффективность.

Считается, что неоценимый вклад в современный коучинг внес Т. Дж. Леонард, организовавший в 1992 г. первый и пока еще (на 2017 г.) самый крупный Университет коучей. Написанная Джоном Уитмором книга «Коучинг высокой эффективности» предварила дорогу коучингу в России [16]. Первым появлением коучинга в России называется 1998 г., когда первая обучающая программа стартовала в Московском филиале Международного Эриксоновского Университета Коучинга [3]. В 2003 г. было фиксировано более 30 компаний, предоставляющих услуги коучинга, и, собственно, пик развития коучинга в России пришелся в основном на первое десятилетние XXI века, хотя и в настоящее время он продолжает активно развиваться [14]. Так по данным Е.И. Гаврилова [3] в 2017 г. в Москве было зафиксировано 497 компаний, использующих коучинг в своей работе, в Санкт-Петербурге 389, в Новосибирске 424, в Красноярске 186, в Омской области 123. Однако следует признать, что распространенность коучинга в России оставляет желать лучшего: так по данным М.В. Гуцала [4] (Кузбасский госуниверситет) число коучей в США на 2004 г. в пересчете на одного жителя страны приходилось 1 коуч на 1000 человек (т.е. в США это такое же обычное явление, как и обращение к врачу или адвокату; в США благодаря работе Международной Федерации коучей эта профессия с 2001 г. признана официальной [6]), однако в России такое соотношение для коучей к числу жителей в 100 раз меньше.

М.В. Гуцал [4] считает возможным принципиально выделить два основных вида коучинга - лайф-коучинг, реализуемый при работе с личными целями человека (в т.ч. и «карьерный коучинг»), и ставящий целью развитие профэффективности бизнес-коучинг.

Выделяется также построенная на опыте западных компаний условная классификация разновидностей коучинга:

- коучинг для руководителей, ориентированный на организацию благоприятных условий для взаимодействия звеньев «руководитель-подчиненный»;

- коучинг-наставничество (менторинг), ориентированный на «взращивание» опытных топменеджеров из молодых в той или иной мере талантливых молодых сотрудников;

- внешний персональный коучинг как форма коуч- 
сопровождения персонального клиента (чаще руководителя) в виде проводимых индивидуальных сессий;

- аналогичный предыдущему, но проводимый внутри консультируемой компании с ее членами внутренний персональный коучинг;

- групповой коучинг (фактически тренинг) по решению назревших и актуальных внутригрупповых задач;

- коучинг функционального состава организации со специальным для конкретной области (менеджмент, финансы и др.) обучением персонала;

- коучинг отдельных проектов, например, при создании рабочей группы;

- системный коучинг, аналогичный групповому, но реализуемый с лицами, имеющими между собой прочные системные связи (проводится с целью их укрепления и отладки взаимодействия) [4].

В.Г. Ваныкина и Т.О. Сундукова [2] считают необходимым провести определенные разграничения для коммуникативных обучающих технологий, отличающихся своей различной структурированностью (наиболее высокая для тренинга, далее - для фасилитации, и меньшая - для коучинга и самая низкая для менторинга), которые используют различные ведущие, порой их не слишком отличая друг от друга.

Проводимый как индивидуально так и в группе $m p e$ нинг предполагает процесс передачи знаний от ведущего (опытного преподавателя) ведомым (обучаемым) с целью освоения новых знаний и навыков, расширения кругозора, улучшения поведенческих тактик, поиска новых сфер применения имеющимся навыкам, и здесь особое место имеют профессиональный инструктаж и уделение внимания практическим занятиям. Таким образом, тренинг прежде всего ориентирован на приобретение и реализацию нового на практике.

Фасилитация ориентирована на процесс объединения людей в группы с целью добиться на практике желаемых результатов за счет построения эффективных моделей поведения во внутригрупповом взаимодействии, т.е. прежде всего, фасилитация реализует себя в создании ситуаций, стимулирующих у членов группы рефлективное мышление (часто посредством постановки перед группой соответствующих, часто риторических, вопросов, необходимых для достижения лучших, и при этом, конкретных результатов).

В отличие от тренинга и фасилитации, а также и менторинга, коучинг считается самым персональным и конфиденциальным процессом обучения, что обусловлено, как минимум, двумя причинами. Это, во-первых, учет для каждого обучающегося индивидуального набора знаний, быстроты восприятия информации, степени об- учаемости и стиля обучения; во-вторых, использование (приемлемость, возможность) результатов коучинга для декларации отзывов об особенностях обучаемого (его сильных и слабых сторонах). Хотя, в целом, результаты коучинга близки для всех остальных видов обучения повышение эффективности деятельности. Коучинг является динамичным процессом, когда преподаватель обращает свое внимание и внимание обучаемого на усовершенствованные и требующие доработки модели поведения, что и формирует индивидуальное стратегию изменений у клиента (развитие навыка в определенной области, усовершенствование деятельности в различных областях за счет открытия в себе ресурсов развития и нового личностного развития.

Менторинг же основан почти на фактическом «копировании» навыка при наблюдении обучаемого за обучающим, т.е. прежде всего он реализуется за счет технического развития навыка. Однако процесс менторинга гораздо шире и также включает в себя наставничество, опирающееся на совместимость и духовное родство учителя и ученика, их личную привязанность и заинтересованность общим делом.

Г.И. Коноплева и А.С. Борщенко [7] на примере организационного коучинга выделяют четыре стадии в моделировании его процесса. На первой стадии формулируется направление обучения и формируется описание его профессиональной компетентности, но здесь вопрос о коучинге вообще поднимается лишь тогда, когда сам обучаемый приходит к осознанию своей потребности в улучшении своей профессиональной деятельности. Вторая стадия называется авторами планированием системы ответственности, и на ней уточняется план личностного развития в ответах на ключевые вопросы: чего именно хотят достичь процессом коучинга, когда и как это будет происходить, и сроки начала и завершения процесса коучинга. Третья стадия посвящена непосредственно реализации процесса коучинга с применением соответствующих ситуации стилей. На четвертой стадии анализируются результаты и производятся выводы по плану личностного развития.

Е.А. Куренкова [11] в выделении этапов коучинга в образовании и всей системы его построения опирается на т.н. «коучинговую стрелу», предложенную М. Аткинсон, включающую в себя «вехи»: раппорт-контракт-создание опыта-действия, шаги-ценность, благодарность.

На этапе раппорта как шага по созданию особых доверительных отношений коучер или преподаватель, использующий методы коучинга, акцентирует обучающихся не на их возможных неудачах, а создает у них максимально возможную установку на успех, и уже на этом этапе в свободном диалоге, без менторства, разъясняются ценности курса, выделенные для изучения 
темы, обозначаются правила совместной работы. Коучинг является элементом обучения или особым подходом к организации и проведению учебного процесса, и в этой связи он может быть использован для большинства изучаемых вузовских дисциплин. Однако коучу необходимо иметь ввиду, что каждое следующее занятие требует возобновления раппорта. На этапе контракта в (обязательной) форме диалога идет прояснение намеченных преподавателем целей, и здесь важно, чтобы коуч не просто заявил собственную позицию обучаемым, а буквально «подключил» их к намеченной цели, что позволяет связать цели коучинга с личной позицией обучаемых, активизировать их мотивацию по погружению в учебный материал. Для этого используются вопросы «пирамиды логических уровней Р. Дилтса»: «- Что есть? - Что я делаю? - Что я могу? Что умею? - Что для меня правильно? А что нет? Что для меня действительно Ценно! - Кто Я? - Залчем я здесь?», либо идея «формата конечного результата» М. Аткинсон: «1) позитивная формулировка конечного результата либо цели; 2) над конечным результатом возможен личный контроль; 3) цель соответствует критериям SMART (конкретна, измерима, достижима, значима, определена по времени); 4) экологичность конечного результата (Как желаемый результат/цель повлияет на вас как личность?)» [11, с.100]. На этапе создания опыта могут быть использованы самые разные инструменты творческого поиска, анализа и решения проблемы, но главным здесь является упор на создание у обучаемого умения самостоятельно мыслить. Этап «действия или шагов» подразумевает осмысление применимости результатов на практике. Этап «ценности» или «благодарности» подразумевает анализ приобретенного с принесением благодарности обучаемых друг другу за приобретенный опыт взаимодействия, что создает условия осознания процесса обучения как полезного и личностно значимого.

Одной из важных сторон технологии коучинга в высшем образовании Е.А. Куренкова [11] называет умение задавать сильные вопросы, способные приглашать к самоанализу, стимулировать поиск ответов и решений, помогать выстраивать логические и причинно-следственные связи, способствующие наиболее глубокому анализу учебной (и любой другой) ситуации. «Анализируя одну и ту же проблему с разных сторон, преподаватель осуществляет процесс управления идеями обучающихся путем расслабленно-строгого лидерства, через создание вдохновляющего инновационного видения. Следовательно, через коучинг в процессе обучения преподаватель и студент могут изменить отношение к заданным ситуациям» [11, с.100-101]. Другие способы организации эффективного взаимодействия с обучаемыми, по данным этого автора, состоят в эмпатическом и глубинном слушании. Но все усилия коуча могут оказаться напрасными, если обучаемый не готов возлагать на себя ответственность за свои результаты и ощущать необходимость потребностей в изменениях.

Е.С. Ваваева [1] считает, что под коучингом в высшем образовании следует понимать:

- направленное на эффективное достижение профессионально значимых для студента целей системное педагогическое сопровождение, реализуемое по возможности большим по своему охвату профессионально подготовленных в сфере коучинга педагогических кадров вуза, благодаря чему у студента вырабатываются гибкость и адаптивность реагирования в изменяющихся сложных и конкурентных требованиях, предъявляемых профессией и рынком;

- осуществляемое со студентом коммуникативное партнерское взаимодействие, помогающее устранить барьеры и социальные стереотипы, обусловленные разницей знаний и социального положения, традиционно задаваемые неличностно ориентированной системой предоставления знаний;

- сочетание у студента непрерывных процессов профессионального образования и личностного развития, способствующее раскрытию личности студента с целью достижения им максимальных результатов;

- технологию, позволяющую в союзе коуча и студента пересмотреть последним свои проблемы развития и переместить из них в зону эффективности решений;

- технологию, также позволяющую студенту ориентироваться на поиск собственных решений в проблемной ситуации;

- модель субъект-субъектного взаимодействия, благодаря которой повышается уровень мотивации и ответственности как у студента, так и у самого преподавателя.

Анализируя представленные в литературе данные (Дж. Уитмор, Э. Парслоу, М. Рэй) Г.И. Коноплева и А.С. Борщенко [7] выделяют следующие принципы коучинга в организации (и мы считаем, что эти принципы могут быть перенесены фактически на все модели коучинга, реализуемые в группах):

- декларация веры в способности обучаемых, благодаря которой они и будут стремиться оправдать доверие через повышение собственной мотивации;

- учитывая взаимную связанность членов любой состоявшейся социальной группы, и, особенно, коллектива, используется принцип единства и взаимосвязи, благодаря которому член группы будет стремиться улучшить собственные результаты, т.к. его собственные достижения будут влиять на достижения группы;

- для общего достижения целей группы использу- 
ется принцип коммуникативного равенства;

- принцип отсутствия готовых решений стимулирует каждого из участников искать самостоятельные ответы на поставленные задачи;

- каждый новый шаг сотрудника может находиться только в зоне его развития, что отвечает принципу поэтапного развития;

- согласно принципа иерархичности развитие человека рассматривается как поэтапное, состоящее из трех уровней (этапов): на первом этапе может быть реализована лишь личная выгода человека, когда другие люди рассматриваются им или как враги, или как помощники; на втором этапе человек отождествляет собственные действия с действиями группы, и здесь с членами своей группы он пытается сотрудничать, а с членами других групп конкурировать; на третьем этапе человек максимально ориентирован на сотрудничество с другими людьми, и вся его деятельность направлена на благо других людей.

Согласно Т.А. Никитиной и М.А. Шаталиной могут быть выделены следующие теоретические и методологические основы коучинга: 1) Сократовские методы диалога Майевтика; 2) Психоаналитическая теория 3. Фрейда; 3) Гуманистический подход в психотерапии (К. Роджерс, А. Маслоу); 4) Методики практикующих спортивных тренеров (Т. Голви); 5) Концепция эмоционального интеллекта (EQ) Д. Голдмана» [14, с.61].

Учитывая неоднозначность восприятия коучинга современной российской аудиторией, и, особенно, ее научной частью, Д.Ю. Титовой [15] была осуществлена попытка систематизировать сложившиеся у нас в стране подходы к пониманию этого явления через обыденное его восприятие прежде всего его участников и «потребителей», а также в междисциплинарном его понимании.

Первый подход является развитием идей французского социолога Ж. Амадо, рассматривающего коучинг в качестве социального феномена, по сути статусноатрибутивного для обеспеченных людей, как своего рода определенного вида психотерапии, как она была модной, особенно психоанализ, примерно во второй и третьей четверти (иногда и позже) XX столетия в США и Европе (вспомним, например, сцену на яхте в фильме, в отечественном его названии «В джазе только девушки», когда герой рассказывает героине Мерелин Монро «Сахарку» об испробованных методах своего лечения): преподносимый как разновидность психотерапии коучинг имеет свою популярность для определенного круга людей не только на Западе, но и в современной России, однако такой подход к коучингу не отражает его вкладов в процессы образования и менеджмента. В противовес взглядам П. Вильямса и Д. Дейвис, сближающих коучинг и психотерапию и фактически называющих коучинг раз- новидностью последней, Д. Клаттербек дистанцирует коучинг не только с психотерапией, но и с наставничеством, а также и с психологическим консультированием, что составляет суть второго подхода к коучингу. Согласно Д. Клаттербеку коучинг отличен от наставничества, во-первых, большей кратковременностью участия в нем обеих сторон (обучающего и обучаемого), во-вторых тем, что и в наставничестве нередко приходится прибегать к сути проявлений коучинга, и это, по сути, его третье отличие: коучинг работает над конкретной задачей по совершенствованию отдельных навыков или характеристик личности. Наставничество же предполагает достаточно широкий спектр реализуемых ролей и зон воздействия, но может в отдельных случаях и проявлять себя в умении выслушать ученика и проявить к нему сочувствие. Но если в психологическом консультировании нередко даются конкретные советы, то в коучинге, и, нередко в наставничестве, стараются побудить ученика принять самостоятельное решение, однако если в коучинге это априорное правило, то в наставничестве допускается дать опирающийся на собственный опыт учителя совет.

Э. Грант выделяет ряд отличий коучинга от психотерапии: коучинг в отличие от психотерапии не имеет дела с людьми, имеющими психические нарушения или психологические проблемы, но ориентирован на лиц, не полностью удовлетворенных своей жизнью и стремящихся к достижению более высоких результатов; коучинг не ориентирован на поиск причин и выявление сложностей развития (преимущественная ориентация психотерапии на прошлое), но направлен на поиск решений (т.е. ориентирован в будущее); наконец, коучинг не занимается клиникой, как например, депрессия.

В третьем подходе делается попытка объединить в коучинге другие техники (или найти «мостки» между ними). Так Д. Клаттербек сближает коучинг с менторством через понятие ученичества, в котором осуществляется передача опыта и знаний от человека, как правило, более старшего по возрасту и более опытного. П. Вильмс и Д. Дэйвис видят в коучинге один из инструментов или понимают его в качестве одного из направлений психотерапии, но принципиально нового и ориентированного на обретение навыков добиваться реализации конкретных поставленных целей и желаний (лайф-коучинг).

Однако сама Д.Ю. Титова [15] считает, что все три перечисленных подхода являются заблуждениями в понимании коучинга: коучинг не может быть представлен в качестве составляющей процесса наставничества (Д. Клаттрбек, О. Горшкова, Е. Бухаркова), т.к. это процессы разного уровня. Но также коучинг не может быть сопоставим и с психотерапией и психологическим консультированием, и это также процессы разного уровня, работающие и с разными проблемами, и с разными условиями 
их возникновения и реализации.

С точки зрения автора (Д.Ю. Титовой) четвертое, появившееся в основном в рамках отечественных исследований понимание коучинга рассматривает его в качестве важного элемента, используемого в процессе обучения в высшей школе, и именно оно является наиболее перспективным для отечественной аудитории применения коучинга, но и здесь у разных специалистов имеются разночтения в понимании коучинга: «Одни специалисты говорят о тренингах «в стиле коучинг»; другие считают коуча по большей части советчиком, помощником, консультантом как в личностном, так и в профессиональном развитии; третьи рассматривают коучинг как личное тренерство и наставничество педагога; четвертые полагают, что коучинг - это своего рода психотерапия» [15, c.179].

И хотя статья этого автора (Д.Ю. Титова) увидела свет 10 лет назад, согласно нашему мнению ситуация с восприятием и пониманием значимости коучинга как явления, существенно облегчающего процессы обучения за счет повышения мотивации обучаемого, его интеллектуальной готовности решать стоящие задачи и активно принимать ответственность за свою жизнь, в нашей стране кардинально не изменилась, в то время как реальные возможности применения коучинга в образовании как средства, «помогающего учиться», де факто не только слабо применяются на практике, но, по нашему мнению, и сильно недооценены.

\section{Выводы}

Отличительной особенностью коучинга является осуществление помощи человеку в его собственном решении проблемы, а не составление рекомендаций по ее решению, что позволяет говорить о коучинге как явлении, помогающем обучаемому выстроить его индивидуальную траекторию развития. Коучинг позволяет организовать субъект-субъектное взаимодействие с профилированием активной позиции у обучаемого. Отличительной особенностью коучинга от хорошо зарекомендовавшего себя в нашей стране наставничества является выработка у обучаемого собственной жизненной позиции, целей, задач и планов при сохранении важной для наставничества партнерских отношений, но вне системы реализации преподавателем, или, точнее, коучем, позиций менторства и директивного давления авторитета, и также вне использования системы подсказок и советов, но при предоставлении обучаемому права выбора в принятии решений и в условиях принятия им ответственности за производимый выбор.

Что касается основной специфики организационного коучинга, то оно, прежде всего, состоит в том, что коучинг создает систему нефинансовой мотивации персонала, что является очень важным дополнением, если в организации уже хорошо функционирует финансовая мотивация персонала.

ЛИТЕРАТУРА

1. Ваваева Е.С. Коучинг как средство формирования коммуникативной успешности обучаемых. // Амурский научный вестник. Комсомольск-на-Амуре: Амурский гуманитарно-педагогический государственный университет. 2013.№1. С.25-31.

2. Ваныкина Г.В., Сундукова Т.О. Тренинг, фасилитация, коучинг и менторинг в непрерывном образовании. // Электронное обучение в непрерывном образовании. Ульяновск: Ульяновский государственный технический университет. 2016. №1. С.648-655.

3. Гаврилов Е.И. Коучинг: основные направления в обучении (на примере Западной Сибири). // Молодежь третьего тысячелетия. Сборник научных статей. 2017. Омск: Омский государственный университет им. Ф.М. Достоевского. 2017. С.74-78.

4. Гуцал М.В. Бизнес-коучинг в России: перспективы развития. // Социальное и экономическое развитие: опыт, проблемы, перспективы. Комсомольск-наАмуре: Амурский гуманитарно-педагогический университет. 2012. №1. С.21-26.

5. Гэллвей Т. Внутренняя игра в теннисе. М.: Пэн. 1986. 230 c.

6. Каменская Н.В., Незамова О.А. Коучинг: теоретические аспекты. // Наука и образование: опыт, проблемы, перспективы развития. Материалы Международной научно-практической конференции. 2015. Красноярск: Красноярский государственный аграрный университет. 2015. С.139-141.

7. К Коноплева Г.И., Борщенко А.С. Коучинг как современный подход к обучению и развитию персонала в организации. // Альманах современной науки и образования. Тамбов: 000 Издательство «Грамота». 2013. №5(72). С. 110-111.

8. Коучинг в действии URL: http://www.lifecoach-online.ru/ (дата обращения 24.08.2020)

9. Коучинг. Часть 1 URL: http://becmology.ru/blog/general/coaching01.htm (дата обращения 24.08.2020)

10. Кузьмина 0. Коучинг и психотерапия - в чем разница? // [Электронный источник] URL: http://mpsy.ru/biblioteka/nashi-stati/kouching-i-psihoterapiya---vchem-raznica.html (дата обращения 24.08.2020)

11. Куренкова Е.А. Коучинг в высшем образовании: проблемы и перспективы. // Актуальные вопросы научной и научно-педагогической деятельности молодых ученых. Сборник научных трудов III Всероссийской заочной научно-практической конференции. 2016. М.: МГЛУ. 2016. С.99-103.

12. Куренкова Е.А. Коучинг как инструмент реализации аксиологического подхода в образовании. // Вестник Костромского государственного университета. Серия: педагогика, психология, социокинетика. 2017. Т.23. №3. С.11-12. 
13. Лири Т., Стюарт М. Технологии изменения сознания в деструктивных культах. Перевод с англ. Под ред. И. Митрофановой. СПб.: Экслибрис. 2002.224 с.

14. Никитина Т.А., Шаталина М.А. Коучинг: условия применения и перспективы развития. // Известия Академии управления: теория, стратегия, инновации. Самара: Самарская академия государственного и муниципального управления. 2011. №3. С.60-64.

15. Титова Д.Ю. Коучинг: основные подходы к исследованию проблемы. // Научные проблемы гуманитарных исследований. 2010. №1. С.176-179.

16. Черняев А.А. Коучинг: сущность, история появления и развитие в России. // Научный поиск в современном мире. Сборник материалов XV Международной научно-практической конференции. 2017. - Махачкала: 000 «Апробация». 2017. С.132-134.

17. Шляков А.В. Рефлексия «не-места» В топологии социального пространства. // Человек. 2018. №5. С. 166-173.

18. Ярославцева А.В. Измененные состояния сознания и нравственность: сходства экзистенциальных функций. // Манускрипт. Тамбов: Грамота. 2019. Т.12. Вып. 10. С.137.

19. 50 принципов коучинга от Томаса Леонарда URL: http://icennosty.blogspot.com/ (дата обращения 24.08.2020).

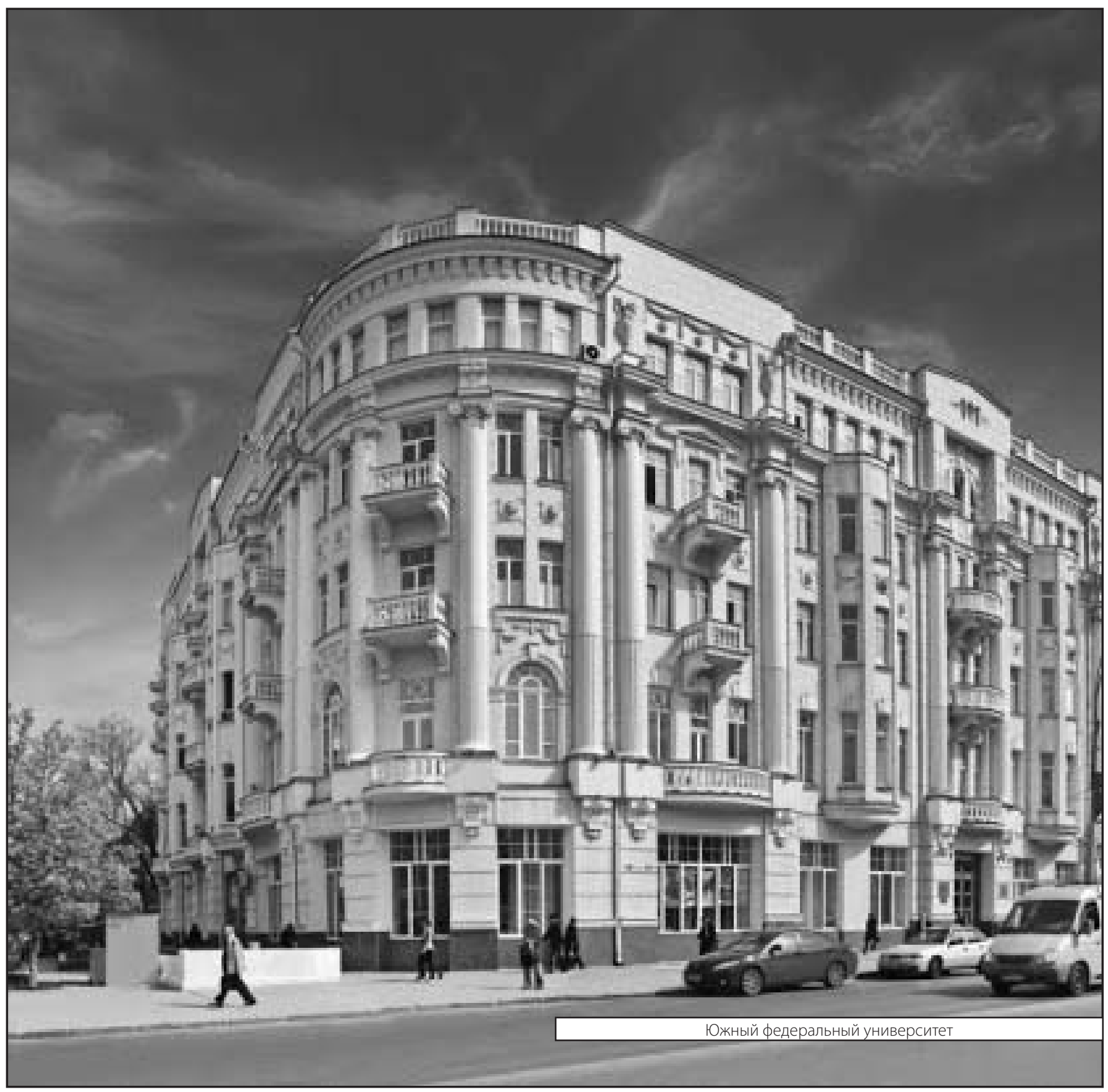

